\title{
Effects of clonidine and morphine on opioid withdrawal in rhesus monkeys
}

\author{
Jonathan L. Katz * \\ Department of Pharmacology, University of Michigan Medical School, Ann Arbor, MI, USA
}

\begin{abstract}
Rhesus monkeys undergoing opioid withdrawal either due to withholding morphine administration for $14 \mathrm{~h}$ or due to administration of naloxone, were treated with either morphine or clonidine. Morphine eliminated all of the withdrawal signs that developed when morphine was withheld for $14 \mathrm{~h}$. Clonidine also eliminated some but not all signs that developed when morphine was withheld. The frequencies of individual signs prior to drug administration were directly related to the minimal doses necessary to eliminate signs for morphine but not for clonidine. Morphine also eliminated most of the signs precipitated by naloxone, whereas clonidine did not eliminate as many of the naloxone-precipitated signs. Additionally, some of the naloxoneprecipitated signs that were eliminated by clonidine were not eliminated by morphine. The present results are consistent with clinical findings indicating an efficacy of clonidine in the treatment of opioid withdrawal through a non-opioid mechanism.
\end{abstract}

Key words: Opioid withdrawal - Morphine - Clonidine Naloxone - Rhesus monkeys

Clonidine, an alpha ${ }_{2}$-adrenoreceptor agonist, has been used effectively in the treatment of opioid dependence (Gold et al. 1978, 1980). In such treatment, clonidine is substituted for opioids during the course of opioid withdrawal and ultimately clonidine administration is terminated. There have been several reports that withdrawal signs and symptoms are minimized during clonidine treatment (Gold et al. 1980; Washton and Resnick 1980; Charney et al. 1981). The therapeutic utility of clonidine has fundamental implications, since previously, only other opioids had been shown in controlled settings to effectively eliminate opioid withdrawal signs and symptoms (Jasinski 1977).

Analysis of effects of clonidine on individual signs and symptoms has indicated that some are affected more than others. For example, in humans many of the autonomic signs of withdrawal are eliminated whereas symptoms such as opioid craving, anxiety, muscle aches, and anorexia can still be present (Charney et al. 1981; Jasinski et al. 1985). Studies of opioid withdrawal in animals have also suggested that some, but not all, signs can be affected by clonidine. In morphine-dependent rats naloxone-precipitated body

* Present address: NIDA Addiction Research Center, P.O. Box 5180, Baltimore, MD 21224, USA shakes were inhibited by clonidine whereas jumping responses were not (Tseng et al. 1975). Additionally, cardiovascular changes (Buccafusco 1983) and diarrhea (Schreier and Burks 1980) precipitated by naloxone in dependent rats can be antagonized by clonidine. In contrast, changes in plasma corticosterone levels precipitated by naloxone are not affected by clonidine (Eisenberg 1983).

The present study was initiated to further examine effects of clonidine on opioid withdrawal. Rhesus monkeys have been used extensively in preclinical assessment of morphine-like dependence-producing capacity of drugs and the characteristic signs of opioid withdrawal have been well documented in this species (Seevers 1936; Villarreal 1973; Aceto et al. 1977). There have been brief reports of effects of clonidine on withdrawal in this species (Aceto et al. 1982; Woods et al. 1981) but no detailed investigations. Therefore, the effects of clonidine on individual withdrawal signs were assessed in this study. Since there may be differences between withdrawal following the discontinuation of opioid treatment and withdrawal precipitated by naloxone, effects of clonidine on each of these syndromes was studied. The efficacy of clonidine was compared to the efficacy of morphine as a positive control.

\section{Materials and methods}

Male and female rhesus monkeys (Macaca mulatta) weighing between 3.0 and $5.0 \mathrm{~kg}$ were housed in groups of four to six per cage (measuring $1.2 \times 2.5 \times 2.1 \mathrm{~m}$ ) in which running water was continuously available. The monkeys were fed daily at 07:00 hours with Purina monkey chow treated with $0.67 \mathrm{mg} / \mathrm{g}$ isoniazid. The monkeys had been trained to receive injections according to a procedure described by Deneau and Seevers (1963) and Villarreal (1973). Every $6 \mathrm{~h}$ $(01: 00,07: 00,13: 00,19: 00$ hours) the cage door was opened and the first monkey left the cage, proceeded to a location in the room characteristic for that individual (typically hanging on the outside of another cage) and received an SC injection below the shoulder. The monkey then proceeded to the other side of the room, through a trap door held open by a technician, at which time the second monkey left the cage and proceeded to its characteristic location in the room and received its injection. After each monkey had received its injection, the trap door was opened and all of the monkeys returned to the cage.

Studies of reversal of withdrawal signs were conducted by withholding morphine injections at 01:00 and 
Table 1. Signs observed on morphine withdrawal

\begin{tabular}{|c|c|}
\hline Withdrawal sign & Description \\
\hline $\begin{array}{l}\text { Atypical position } \\
\text { in cage }\end{array}$ & $\begin{array}{l}\text { Each individual had one particular } \\
\text { portion of the cage in which it was } \\
\text { typically located, such as left side on } \\
\text { perch or floor, etc. This sign was } \\
\text { scored when the subject was not in its } \\
\text { typical position. }\end{array}$ \\
\hline Holding abdomen & $\begin{array}{l}\text { When sitting on haunches, } \\
\text { maintaining forearms within knees and } \\
\text { against the abdomen. }\end{array}$ \\
\hline Grimacing & $\begin{array}{l}\text { Teeth bared with jaws closed and } \\
\text { angles of the mouth retracted. }\end{array}$ \\
\hline Dysphoric facies & $\begin{array}{l}\text { Facial expression of extreme } \\
\text { distress. }\end{array}$ \\
\hline Provoked screams & $\begin{array}{l}\text { Screaming provoked by another } \\
\text { subject. }\end{array}$ \\
\hline Rigidity & $\begin{array}{l}\text { Slow stiff movement, especially } \\
\text { observed in hindlimbs. }\end{array}$ \\
\hline $\begin{array}{l}\text { Cooperativity } \\
\text { during handling }\end{array}$ & $\begin{array}{l}\text { This behavior was graded as } \\
\text { affected if the subject was noticeably } \\
\text { less cooperative than usual during } \\
\text { handling; particularly if the subject } \\
\text { tried to scratch or bite the technician. }\end{array}$ \\
\hline $\begin{array}{l}\text { Unusual position } \\
\text { during handling }\end{array}$ & $\begin{array}{l}\text { This sign was graded as present if } \\
\text { the subject did not go to its } \\
\text { characteristic position during the } \\
\text { handling procedure. Most often the } \\
\text { monkey was on the floor rather than } \\
\text { hanging from the cage wall. }\end{array}$ \\
\hline Abdominal defense & $\begin{array}{l}\text { Presence of rigidity in the } \\
\text { abdominal musculature }\end{array}$ \\
\hline Vocalization & $\begin{array}{l}\text { Vocalization during palpation of } \\
\text { the abdomen. }\end{array}$ \\
\hline
\end{tabular}

07:00 hours. By 09:00 hours subjects were showing a withdrawal reaction that could be either alleviated or exacerbated by treatment with opioid agonists or antagonists, respectively. Presence or absence of each withdrawal sign was assessed by two independent trained observers, blind to the treatment conditions and to each other. The observers first surveyed the subjects in their cages and then handled each of the monkeys according to a procedure similar to that followed during injections. However, in the handling procedure, the monkeys abdomen was palpated by each technician in order to assess the rigidity of the abdominal musculature and the reaction of the monkey. At 09:00 hours, in addition to handling, the subjects were also injected with a dose of either morphine or clonidine. Signs of withdrawal were assessed at 30 and $60 \mathrm{~min}$ after the injection and at each following $1-\mathrm{h}$ interval for at least $4 \mathrm{~h}$. Data reported here were collected at $2 \mathrm{~h}$ following the injection. With clonidine, four monkeys were studied at each dose level by two independent observers. Thus, for a given sign there was typically a maximal number of positive occurrences of eight (four subjects $\times$ two observations). With morphine, 12 subjects were studied at each dose except $1.0 \mathrm{mg} / \mathrm{kg}$ (seven subjects) and $3.0 \mathrm{mg} / \mathrm{kg}$ (four subjects). The frequency of a sign was considered to be affected by drug if after drug administration the average frequency was outside $\pm 1 \mathrm{SD}$ of the average frequency prior to drug administration. The signs observed and the defining characteristics of those that are not self explanatory are given in Table 1.

Precipitated withdrawal was studied at 09:00 hours, $2 \mathrm{~h}$ after a regular morphine injection. Monkeys were graded for withdrawal signs and then injected at 30-min intervals with increasing doses of naloxone. Prior to each injection the presence of each withdrawal sign was assessed by treatment-blind observers. In studies of the modification of precipitated withdrawal, either morphine or clonidine was injected $10 \mathrm{~min}$ before the first dose of naloxone.

Morphine sulfate, naloxone hydrochloride and clonidine hydrochloride were dissolved in distilled water. All drugs were administered $\mathrm{SC}$ and doses are expressed as $\mathrm{mg}$ of the salt per $\mathrm{kg}$ body weight.

\section{Results}

Signs observed reliably after $14 \mathrm{~h}$ of morphine deprivation were: lying on side, atypical position in cage, holding abdomen, avoiding others, grimacing and dysphoric facies. During the handling procedure the cooperativity of the monkeys was decreased, they did not proceed to their characteristic position for handling, the abdominal musculature was rigid and the subjects vocalized when the abdomen was palpated. Prior administration of morphine decreased the frequency of each of these signs (Fig. 1, filled symbols). At the highest dose studied, most of the signs of withdrawal were eliminated. Although vocalization was not entirely eliminated, the $10.0 \mathrm{mg} / \mathrm{kg}$ dose reduced it to a level comparable to that observed when no drugs were administered.

Clonidine also altered the withdrawal syndrome. Signs observed in the home cage such as lying on side, atypical position in cage, grimacing, holding abdomen and dysphoric facies were decreased in frequency by some doses of clonidine (Fig. 1, open symbols). At the highest dose of clonidine studied, lying on side, atypical position in cage and holding abdomen were observed at higher frequencies than at lower clonidine doses. During the handling procedure cooperativity, unusual position and abdominal defense were also affected by clonidine whereas vocalization was not. At the highest dose unusual position and abdominal defense scores were comparable to preinjection values. Not all of the withdrawal signs that were eliminated by morphine were also eliminated by clonidine (Table 2).

The relationship between frequency of the sign prior to drug administration and the minimal dose necessary to virtually eliminate the sign is shown in Fig. 2. Signs observed in the cage prior to handling are shown by filled points; those observed during handling are shown by open points. For vocalization the dose plotted is $10.0 \mathrm{mg} / \mathrm{kg}$ since that dose, although not eliminating the sign, returned the frequency to that observed in subjects not undergoing withdrawal. Generally, the greater the frequency of the sign before drug administration, the higher the morphine dose necessary to virtually eliminate the sign. For example, holding abdomen and avoiding others were the most frequent of signs observed in the cage prior to handling. A morphine dose of $10.0 \mathrm{mg} / \mathrm{kg}$ was required to eliminate these signs. In contrast, lying on side and a typical position in cage were less frequent and required morphine doses of 1.7 and $1.0 \mathrm{mg} / \mathrm{kg}$, respectively, in order to eliminate them. As can be seen in Fig. 2, there is a direct relationship between the two variables when morphine was studied $(r=0.84, P<$ 0.005 ). In contrast with clonidine, there was no relationship 


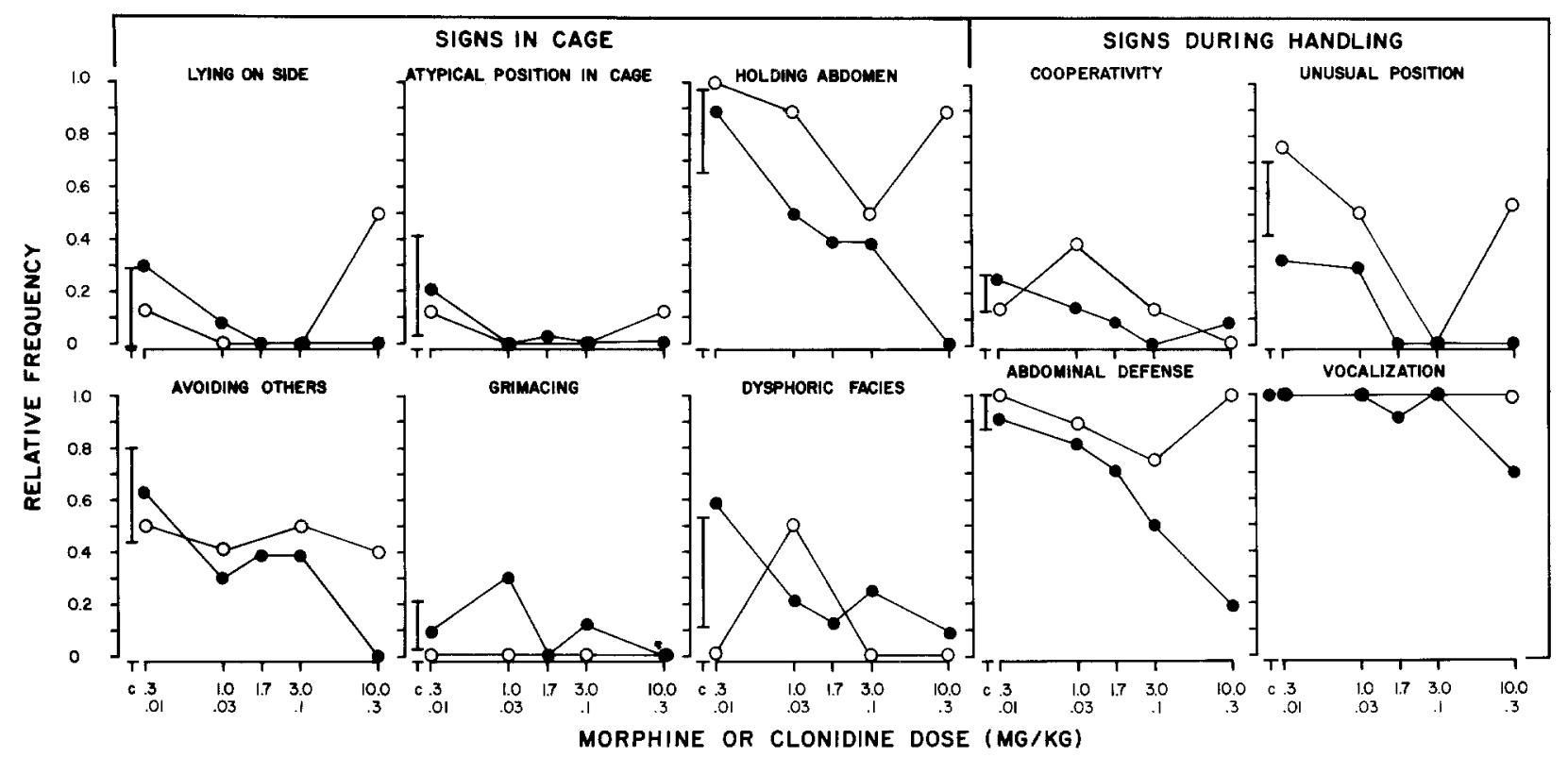

Fig. 1. Effects of morphine or clonidine on frequency of various withdrawal signs in rhesus monkeys observed in the subjects in their home cages or during the handling procedure. Each point is the mean of observations by two independent treatment-blind observers of at least four monkeys at each dose. Data shown were collected at $2 \mathrm{~h}$ following injection. The control points are for observations immediately before injections

Table 2. Summary of withdrawal signs and minimal doses necessary to alter their frequency

\begin{tabular}{|c|c|c|c|c|}
\hline & \multicolumn{2}{|c|}{$\begin{array}{l}14 \mathrm{~h} \text { since } \\
\text { morphine }\end{array}$} & \multicolumn{2}{|c|}{$\begin{array}{l}\text { Naloxone- } \\
\text { precipitated } \\
\text { withdrawal }\end{array}$} \\
\hline & $\begin{array}{l}\text { Mor- } \\
\text { phine }\end{array}$ & $\begin{array}{l}\text { Clo- } \\
\text { nidine }\end{array}$ & $\begin{array}{l}\text { Mor- } \\
\text { phine }\end{array}$ & $\begin{array}{l}\text { Clo- } \\
\text { nidine }\end{array}$ \\
\hline Lying on side & 1.7 & 0.03 & 10.0 & 0.3 \\
\hline Atypical position-cage & 1.0 & 0.03 & 3.0 & 0.03 \\
\hline Holding abdomen & 1.0 & 0.1 & 10.0 & \\
\hline Avoiding others & 1.0 & & & \\
\hline Grimacing & 1.7 & 0.01 & 3.0 & 0.03 \\
\hline Dysphoric facies & 10.0 & 0.01 & & 0.03 \\
\hline Pacing $^{\mathrm{a}}$ & & & 10.0 & 0.03 \\
\hline Crawling $^{\mathbf{a}}$ & & & 10.0 & 0.03 \\
\hline Provoked screams ${ }^{a}$ & & & 3.0 & 0.03 \\
\hline Dyspnea $^{a}$ & & & 10.0 & 0.3 \\
\hline Retching $^{a}$ & & & 10.0 & \\
\hline Erection/Masturbation $^{\text {a }}$ & & & 10.0 & \\
\hline Miosis $^{a}$ & & & & 0.03 \\
\hline Rigidity $^{\text {a }}$ & & & 3.0 & 0.3 \\
\hline Cooperativity-handling & 1.7 & 0.3 & 10.0 & \\
\hline Unusual position-handling & 1.7 & 0.1 & 3.0 & \\
\hline Abdominal defense & 1.0 & 0.1 & 10.0 & 0.03 \\
\hline Vocalization & 1.7 & & & \\
\hline
\end{tabular}

a Sign observed reliably only during precipitated withdrawal

between frequency of the sign prior to drug administration and dose of clonidine necessary to virtually eliminate the sign $(r=0.30)$.

Precipitated withdrawal. During precipitated withdrawal many more signs were observed while the subjects were in their cages prior to handling than in the studies in which morphine injections were withheld for $14 \mathrm{~h}$. Typically, these signs increased in frequency with increasing naloxone dose. For some signs (e.g., lying on side, holding abdomen, erection/masturbation) the frequency reached a maximum at a dose of naloxone below the highest dose administered. Frequencies of other signs (e.g., miosis, dysphoric facies, tremor) were increased above zero only at the highest doses studied. For the signs observed during both 14-h morphine withdrawal and naloxone-precipitated withdrawal there was no relationship between relative frequency at $14 \mathrm{~h}$ post morphine and the minimal naloxone dose necessary to increase the frequency of the sign above baseline $(r=0.35)$.

For most signs, pretreatment with morphine altered the naloxone dose-effect curve (Fig. 3). Among the signs affected by morphine pretreatment, there were differences in sensitivity to the effects of morphine. For example, some signs (e.g., erection/masturbation, rigidity) were completely eliminated by pretreatment with suitable doses of morphine. For other signs (e.g., lying on side, pacing, provoked screams, dyspnea) the dose-effect curves were shifted to the right in a manner that suggested competitive antagonism of the effects of naloxone by morphine. Additionally, the degree of the shift was often related to the dose of morphine. For still other signs (e.g., dysphoric facies, miosis), the naloxone dose-effect curve was not altered by morphine pretreatment. Finally, effects of naloxone on avoidance of others was enhanced by pretreatment with morphine.

Effects of naloxone on most signs during the handling procedure were also antagonized by morphine (Fig. 3). Effects on vocalization were complex, since subjects vocalized at a high frequency without naloxone administration, and morphine alone decreased the frequency of vocalization (points above C, Fig. 3, Vocalization). To analyze further the interactions of morphine and naloxone on this measure, the control frequencies of vocalization (values of points above C) were subtracted from the frequencies observed after corresponding successive doses of naloxone. When this measure of change in frequency of vocalization was consid- 


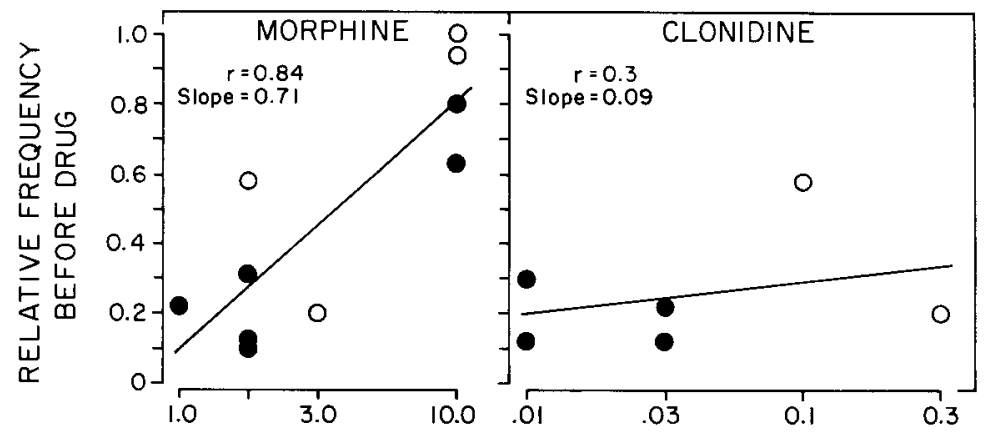

MINIMAL DOSE NECESSARY TO ELIMINATE SIGN (MG/KG, LOG SCALE)
Fig. 2. Relationship between the relative frequency of a withdrawal sign prior to drug administration and the minimal dose of agonist necessary to eliminate the sign. Filled points represent withdrawal signs observed in the cage; open points represent withdrawal signs observed during the handling procedure. Only those signs that were affected are shown for clonidine. For vocalization, the minimal dose is one that reduced the frequency to that observed prior to drug administration. Note that although there was a direct relation between the two variables with morphine, there was no relation with clonidine

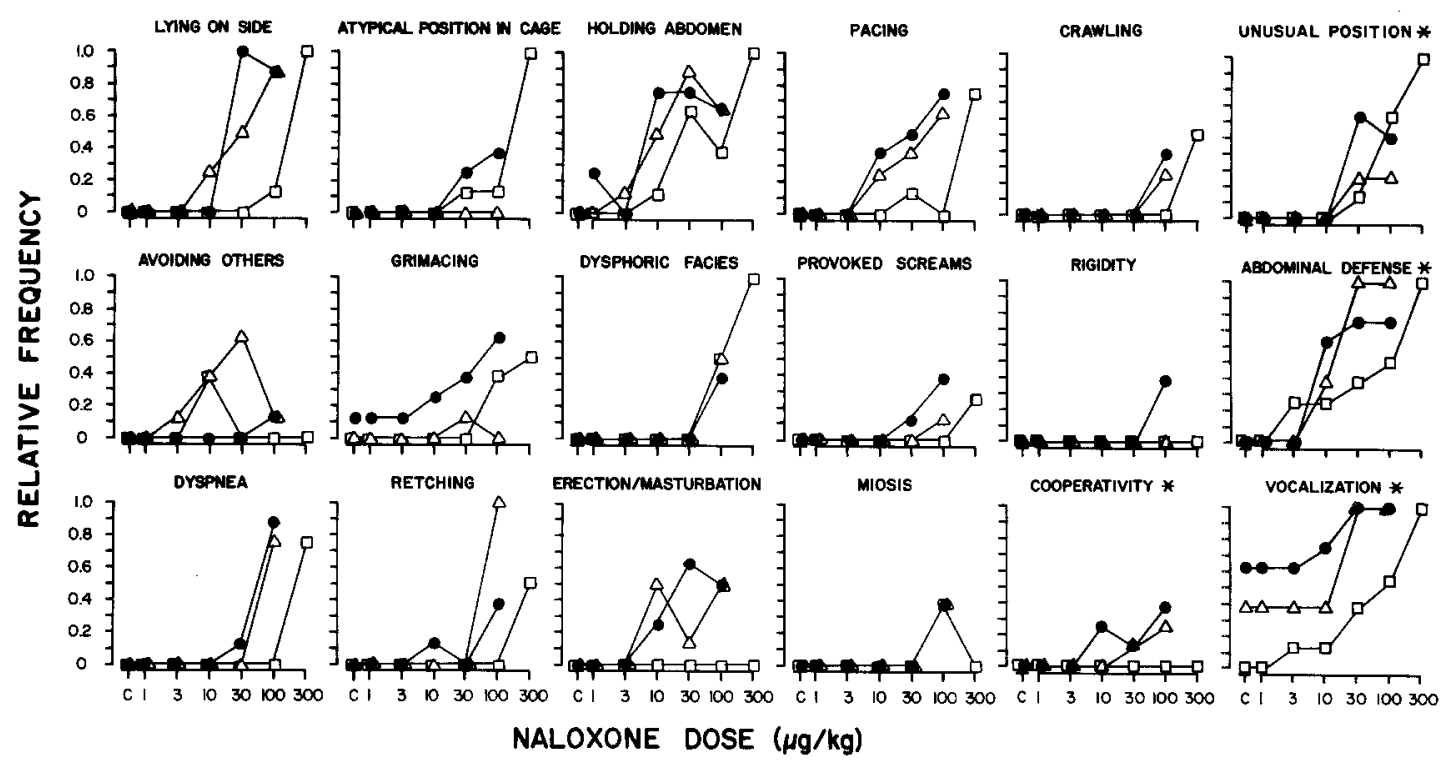

Fig. 3. Effects of pretreatment with morphine on frequencies of various withdrawal signs precipitated by naloxone in rhesus monkeys. Doses of naloxone were administered in a cumulative manner each $30 \mathrm{~min}$. Observations were made by two independent treatment-blind observers immediately prior to each injection. Signs observed during the handling procedure are indicated by an asterisk. Morphine was injected $10 \mathrm{~min}$ before the first dose of naloxone. Each point is the mean of observations of four monkeys. Filled circles: naloxone alone; open triangles: $3.0 \mathrm{mg} / \mathrm{kg}$ morphine; open squares: $10: 0 \mathrm{mg} / \mathrm{kg}$ morphine

ered, morphine did not antagonize effects of naloxone on vocalization (Table 3 ).

Clonidine also altered the effects of naloxone on frequencies of various withdrawal signs (Fig. 4). As with morphine, there were differences among the signs in the manner in which clonidine altered the naloxone dose-effect curve. For several signs (e.g., lying on side, pacing, grimacing) the naloxone dose-effect curves were shifted to the right, whereas for other signs (e.g., atypical position in cage, dysphoric facies), over the range of naloxone doses studied, the signs were absent. The effects of naloxone on frequency of some signs (e.g., retching, erection/masturbation) were not appreciably altered by clonidine pretreatment. As with morphine, the effect of naloxone on avoidance of other monkeys was enhanced by clonidine pretreatment. The frequency of holding abdomen was enhanced by pretreatment with the highest dose of clonidine.

Effects of naloxone on abdominal defense were antagonized by clonidine pretreatment whereas effects on cooperativity and position during handling were not affected (Fig. 4). Clonidine alone affected the frequency of yocalization. If the naloxone-induced change in frequency of vocali-
Table 3. Frequency of vocalization after successive doses of naloxone administered alone or after pretreatment with morphine or clonidine. Each value is the frequency minus the frequency observed prior to naloxone administration

\begin{tabular}{lllllll}
\hline $\begin{array}{l}\text { Naloxone } \\
\text { dose } \\
(\mu \mathrm{g} / \mathrm{kg})\end{array}$ & $\begin{array}{l}\text { Naloxone } \\
\text { alone }\end{array}$ & \multicolumn{2}{l}{ With morphine } & & \multicolumn{2}{l}{ With clonidine } \\
\cline { 6 - 7 } \cline { 6 - 7 } & & 3.0 & 10.0 & & 0.03 & 0.3 \\
\hline 1 & 0 & 0 & 0 & 0 & 0 \\
3 & 0 & 0 & 0.13 & & 0 & 0 \\
10 & 0.12 & 0 & 0.13 & & 0.14 & 0.25 \\
30 & 0.37 & 0.62 & 0.38 & & 0.25 & 0.62 \\
100 & 0.37 & 0.62 & 0.55 & & 0.25 & 0.75 \\
300 & & & 1.00 & & \\
\hline
\end{tabular}

zation is considered, clonidine did not appreciably antagonize effects of naloxone, but rather the higher dose of clonidine enhanced effects of naloxone (Table 3). Clonidine did not eliminate as many of the naloxone-precipitated signs as morphine did. However, clonidine affected some signs that morphine did not affect (Table 2). 


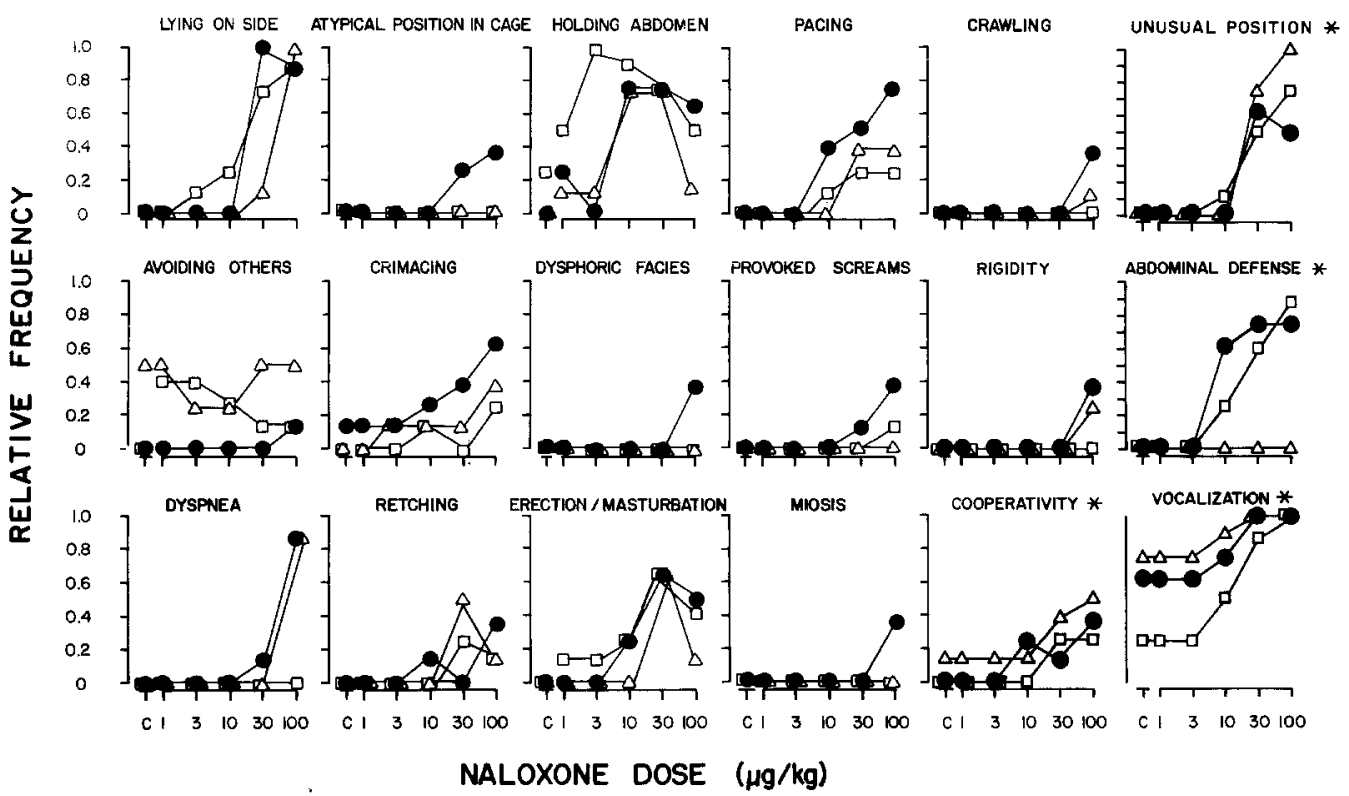

Fig. 4. Effects of pretreatment with clonidine on frequencies of various withdrawal signs precipitated by naloxone in rhesus monkeys. Filled circles: naloxone alone; open triangles: $0.03 \mathrm{mg} / \mathrm{kg}$ clonidine; open squares: $0.3 \mathrm{mg} / \mathrm{kg}$ clonidine. Other details as in Fig. 3

\section{Discussion}

In the present study, both morphine and clonidine modified the signs of opioid withdrawal in rhesus monkeys. Morphine modified a wider spectrum of signs than did clonidine and, for morphine, the dose that completely eliminated a sign was directly related to the frequency of the sign prior to drug administration. Both morphine and clonidine also modified naloxone-precipitated withdrawal and, as with studies of withdrawal from morphine, morphine modified a wider range of signs.

Several studies of precipitated withdrawal have noted similarities and differences between precipitated withdrawal and withdrawal due to the cessation of morphine administration (see reviews by Martin and Jasinksi 1977 and Katz and Valentino 1985). Most studies have shown more signs are observed during precipitated withdrawal or that, of the signs observed, those during precipitated withdrawal were of a greater severity or intensity. Thus, in studies in which the only measure is a total withdrawal score computed from individual signs, potential differences between the two types of withdrawal syndromes may be obscured. In the present study, all signs observed after withholding morphine were also observed during precipitated withdrawal; however, the precipitated withdrawal syndrome included several additional signs. Further, not all of the signs affected by morphine during the two syndromes were identical, suggesting a functional difference between the two syndromes. Thus, it remains important to determine the effects of treatments on individual withdrawal signs.

Himmelsbach (1941) first suggested that a drug that completely reversed signs of morphine withdrawal would produce a type of dependence similar to that of morphine. Deneau (1956), however, found that several opioids differentially affect some morphine withdrawal signs. Meperidine and several of its analogs, for example, reverse autonomic signs of withdrawal only at doses higher than those necessary to reverse other signs of withdrawal. Some drugs have effects that may obscure the assessment of whether the drug alleviated withdrawal. For example, propoxyphene reverses many withdrawal signs; however, at higher doses there are signs of motor excitation that may be pro-convulsant (Deneau 1956). Thus, not all opioids will have effects that completely resemble those of morphine in reversing all morphine withdrawal signs. The feature that identifies opioids is the range of signs that is reversed (Villarreal 1973; Seevers and Deneau 1963). Clearly clonidine reversed fewer signs than did morphine, and by a non-opioid mechanism. The non-opioid mechanism confers on clonidine its therapeutic utility in the treatment of opioid withdrawal.

The utility of clonidine in treatment of patients undergoing opioid withdrawal has led to speculation on the mechanism by which clonidine modifies the withdrawal syndrome. Recently, a series of papers has suggested the locus coeruleus as an important brain site in the generation of opioid withdrawal reactions (Redmond 1981; Redmond and Huang 1982). This conclusion stems from the purported similarity of signs observed during opioid withdrawal and those observed after stimulation of the locus coeruleus. Although a similar constellation of signs resulting from the independent variables suggests a functional equivalence of those two variables, it is not conclusive evidence. In such circumstances, it is exceedingly important to determine, as precisely as possible, how similar the behavioral syndromes are. Additionally, it has been claimed that clonidine similarly reverses the signs produced by stimulation of the locus coeruleus and those observed during opioid withdrawal (Redmond 1981; Redmond and Huang 1982). Under those circumstances, it is important to determine how similar the effects of independent variables such as drug administration are on the two syndromes.

Descriptions of behavioral effects of stimulation of the locus coeruleus have been reported in chair-restrained stump-tailed macaques (Redmond et al. 1976; Redmond and Huang 1979). Signs observed include: widening of the eyes, increased movement, chewing, teeth grinding, grasping of the chair, scratching, self-mouthing, yawning, hair pulling, hand wringing, escape struggling and spasmodic jerks of the body. In addition, pupillary dilatation, piloerection, increased blood pressure, and increased heart rate 
have been reported (Redmond 1981). Of these signs, only increased movement was observed in the present study, although it is unclear whether the pacing presently observed is analogous to increased movement in chair restrained subjects. Yawning and piloerection have also been observed during opioid withdrawal (Villarreal and Karbowski 1974), although in the present study these signs were not observed reliably enough to quantify. Some of the signs observed after stimulation of the locus coeruleus are signs observed in rhesus monkeys after administration of opioid agonists rather than during opioid withdrawal. These signs include pupillary dilatation and scratching. Thus, although some similarities exist in the syndrome produced by stimulation of the locus coeruleus and that produced by opioid withdrawal, there are substantive differences.

Clonidine has been reported to decrease the effects of locus coeruleus stimulation as well as the effects of opioid withdrawal suggesting a functional equivalence of the two. The effects of clonidine on locus coeruleus stimulation however, were on a composite score for the behaviors listed above (Redmond 1981) and, therefore, it is unclear how closely the effects correspond to the effects on behaviors observed during withdrawal. In the present study, both clonidine and morphine affected some of the same withdrawal signs; however, not all of the signs were affected similarly. A composite score would obscure the present differences between the two drugs. Quantitative studies comparing effects of clonidine on individual behaviors observed during opioid withdrawal would allow a better comparison of the two syndromes.

It is clear, from the present data, that clonidine, over a range of doses does not affect all aspects of the opioid withdrawal syndrome in rhesus monkeys. Doses were studied that, extrapolating from rodents (Svensson et al. 1975), were likely to affect locus coeruleus activity. Thus, it appears that the withdrawal syndrome is not due entirely to activation of the locus coeruleus.

Acknowledgments. This study was supported in part by U.S.P.H.S Grant DA-00254 to the University of Michigan Medical School. Technical assistance was provided by $\mathrm{Mr}$. James $\mathrm{E}$. Goodrich and Mr. Fred Adams. Statistical assistance was provided by Ms. Terrie Kocher. Ms. Donna Shelton provided assistance in preparation of the manuscript.

\section{References}

Aceto MD, Flora RE, Harris LS (1977) The effects of naloxone and nalorphine during the development of morphine dependence in rhesus monkeys. Pharmacology 15:1-9

Aceto MD, Harris LS, May EL (1982) Dependence studies of new compounds in the rhesus monkey, rat, and mouse (1981). NIDA Research Monograph Series 41:338-380

Buccafusco JJ (1983) Cardiovascular changes during morphine withdrawal in the rat: Effects of clonidine. Pharmacol Biochem Behav 18:209-215

Charney DS, Sternberg DE, Kleber HD, Heninger GR, Redmond Jr DE (1981) The clinical use of clonidine in abrupt withdrawal from methadone. Arch Gen Psychiatry 38:1273-1277

Deneau GA (1956) An analysis of factors influencing the development of physical dependence to narcotic analgesics in the rhesus monkey with methods for predicting physical dependence liability in man. Doctoral Thesis, University of Michigan

Deneau GA, Seevers MH (1963) Evaluation of new compounds for morphine-like physical dependence capacity. In: Proceedings of the 25th Annual Meeting Committee on Problems of Drug Dependence, NAS, Washington, D.C., Addendum 25
Eisenberg RM (1983) Influence of clonidine on the acute dependence response elicited in naive rats by naloxone. Life Sci 32:1547-1552

Gold MS, Pottash AC, Sweeney DR, Kleber HD (1980) Opiate withdrawal using clonidine. JAMA $243: 343-346$

Gold MS, Redmond Jr DE, Kleber HD (1978) Clonidine in opiate withdrawal. Lancet i: $929-930$

Himmelsbach CK (1941) The effects of certain chemical changes on the addiction characteristics of drugs of the morphine, codeine series. J Pharmacol Exp Ther 71:41-48

Jasinski DR (1977) Assessment of the abuse potentiality of morphinelike drugs (methods used in man). In: Martin WR (ed) Drug Addiction I. Handbook of experimental pharmacology, vol 45 I. Springer-Verlag, Berlin, pp 197-258

Jasinski DR, Johnson RE, Kocher TR (1985) Clonidine in morphine withdrawal: differential effects on signs and symptoms. Arch Gen Psychiatry 42:1063-1066

Katz JL, Valentino RJ (1985) Pharmacological and behavioral factors in opioid dependence in animals. In: Goldberg SR, Stolerman IP (eds) Behavioral analysis of drug dependence, Academic Press, New York (in press)

Martin WR, Jasinski DR (1977) Assessment of abuse potential of narcotic analgesics in animals. In: Martin WR (ed) Drug Addiction I, Handbook of experimental pharmacology, Vol $45 /$ I, Springer-Verlag, Berlin pp 159-196

Redmond Jr DE (1981) Clonidine and the primate locus coeruleus: evidence suggesting anxiolytic and anti-withdrawal effects. In: Lal H, Fielding S (eds) Psychopharmacology of clonidine, Alan R Liss, Inc, New York, pp 147-163

Redmond Jr DE, Huang YH (1979) New evidence for a locus coeruleus-norepinephrine connection with anxiety. Life Sci 25:2149-2162

Redmond Jr DE, Huang YH (1982) The primate locus coeruleus and effects of clonidine on opiate withdrawal. J Clin Psychiatry $43: 25-29$

Redmond Jr DE, Huang YH, Snyder DR, Maas JW (1976) Behavioral effects of stimulation of the nucleus locus coeruleus in the stump-tailed monkey, Macaca arctoides. Brain Res 116:502-510

Schreier WA, Burks TF (1980) Clonidine prevents naloxone-precipitated morphine withdrawal diarrhea. Pharmacologist $22: 304$

Seevers MH (1936) Opiate addiction in the monkey. I. Methods of study. J Pharmacol Exp Ther 56:147-156

Seevers MH, Deneau GA (1963) Physiological aspects of tolerance and physical dependence. In: Root WS, Hofmann FG (eds) Physiological Pharmacology, Vol 1, Academic Press, New York, pp 565-640

Svensson TH, Bunney BS, Aghajanian GK (1975) Inhibition of both noradrenergic and serotonergic neurons in brain by the agonist clonidine. Brain Res 92:291-306

Tseng L-F, Loh HH, Wei ET (1975) Effects of clonidine on morphine withdrawal in the rat. Eur J Pharmacol 30:93-99

Villarreal JE (1973) The effects of morphine agonists and antagonists on morphine-dependent rhesus monkeys. In: Kosterlitz HW, Collier HOJ, Villarreal JE (eds) Agonist and antagonist action of narcotic analgesic drugs. University Park Press, Baltimore pp 73-93

Villarreal JE, Karbowski MG (1974) The actions of narcotic antagonists in morphine-dependent rhesus monkeys. In: Braude MC, Harris LS, May JP, Smith and Villarreal JE (eds) Narcotic antagonists. Advances in biochemical psychopharmacology, vol 8, Raven Press, New York, pp 273-289

Washton AM, Resnick RB (1980) Clonidine for opiate detoxification: Outpatient clinical trials. Am J Psychiatry 137:1121-1122

Woods JH, Medzihradsky F, Smith CB, Young AM, Swain HH (1981) Annual report: Evaluation of new compounds for opioid activity (1980). NIDA Research Monograph Series 34:327-366

Received December 7, 1984; Final version June 18, 1985 